\title{
Sedimentation processes in a coral reef embayment: Hanalei Bay, Kauai
}

\author{
C.D. Storlazzi ${ }^{\text {a,* }}$, M.E. Field ${ }^{\text {a }}$, M.H. Bothner ${ }^{b}$, M.K. Presto ${ }^{\text {a }}$, A.E. Draut ${ }^{a}$ \\ a U.S. Geological Survey, Pacific Science Center, 400 Natural Bridges Drive, Santa Cruz, CA 95060, United States \\ ${ }^{\mathrm{b}}$ U.S. Geological Survey, Woods Hole Science Center, 384 Woods Hole Road, Woods Hole, MA 02543, United States
}

\section{A R T I C L E I N F O}

\section{Article history:}

Received 9 September 2008

Received in revised form 8 May 2009

Accepted 28 May 2009

Communicated by: J.T. Wells

\section{Keywords:}

coral reefs

winds

waves

currents

sediment traps

sedimentation

USA

Hawaii

Kauai

\begin{abstract}
A B S T R A C T
Oceanographic measurements and sediment samples were collected during the summer of 2006 as part of a multi-year study of coastal circulation and the fate of terrigenous sediment on coral reefs in Hanalei Bay, Kauai. The goal of this study was to better understand sediment dynamics in a coral reef-lined embayment where winds, ocean surface waves, and river floods are important processes. During a summer period that was marked by two wave events and one river flood, we documented significant differences in sediment trap collection rates and the composition, grain size, and magnitude of sediment transported in the bay. Sediment trap collection rates were well correlated with combined wave-current near-bed shear stresses during the non-flood periods but were not correlated during the flood. The flood's delivery of fine-grained sediment to the bay initially caused high turbidity and sediment collection rates off the river mouth but the plume dispersed relatively quickly. Over the next month, the flood deposit was reworked by mild waves and currents and the fine-grained terrestrial sediment was advected around the bay and collected in sediment traps away from the river mouth, long after the turbid surface plume was gone. The reworked flood deposits, due to their longer duration of influence and proximity to the seabed, appear to pose a greater long-term impact to benthic coral reef communities than the flood plumes themselves. The results presented here display how spatial and temporal differences in hydrodynamic processes, which result from variations in reef morphology and orientation, cause substantial variations in the deposition, residence time, resuspension, and advection of both reef-derived and fluvial sediment over relatively short spatial scales in a coral reef embayment.
\end{abstract}

Published by Elsevier B.V.

\section{Introduction}

Hermatypic coral reefs typically grow in relatively clear, oligotrophic waters. Land use practices such as agriculture, overgrazing, and urban development lead to significant alterations in the quantity and quality of sediment delivered to the coastal ocean and coral reefs (e.g., McCulloch et al., 2003). Terrestrial sediment runoff in developed coastal regions may also include nutrients, fertilizers, pesticides, herbicides, metals, and pathogens, and although the effects of sediment-associated contaminants on marine ecosystems may be significant (e.g., Harrington et al., 2005; Jones, 2005), the ecosystem impacts and sediment-toxicity guidelines are not well constrained for many compounds (e.g. Bjorgesaeter and Gray, 2008). By itself, finegrained terrestrial sediment can increase turbidity, which in turn, decreases light available for photosynthesis and can create physiological stress or even coral mortality (Marszalek, 1981; Buddemeir and Hopley, 1988; Acevedo et al., 1989; Fortes, 2000; Phillip and Fabricius, 2003; Piniak, 2007; Piniak and Brown, 2008). Under conditions that

\footnotetext{
* Corresponding author. Tel.: +1 8314274721.

E-mail address: cstorlazzi@usgs.gov (C.D. Storlazzi).
}

permit sediment accumulation, corals can be additionally stressed due to the allocation of energy required to remove sediment particles, sites for new coral recruitment can be eliminated, and coral colonies can be buried (e.g. Rogers, 1990; Fabricius, 2005).

The studies by Marszalek (1981) and Ogston et al. (2004) and the syntheses by Rogers (1990), Phillip and Fabricius (2003), and Fabricius (2005) note that the magnitude and duration of turbidity and sedimentation play a significant factor in the ecological response of both individual corals and coral reef ecosystems. Phillip and Fabricius (2003) and Fabricius (2005) also noted that an important factor contributing to the level of degradation caused by a given stressor is the level of exposure, which is a function of the stressor's concentration and residence time, both of which are influenced by hydrodynamic processes. A number of studies have investigated sediment delivery by rivers (e.g., Milliman and Syvitski, 1992) and sediment dynamics in river plumes (e.g., Geyer et al., 2000; Warrick et al., 2008). These have primarily focused on the influence of physical forcing and flood dynamics on balance between freshwater buoyancy and sediment settling in the coastal zone.

Wolanski (1994), Fabricius and Wolanski (2000), and Wolanski et al. (2003) have conducted detailed investigations of fine-grained sediment delivery by river plumes to coral reef environments. These 


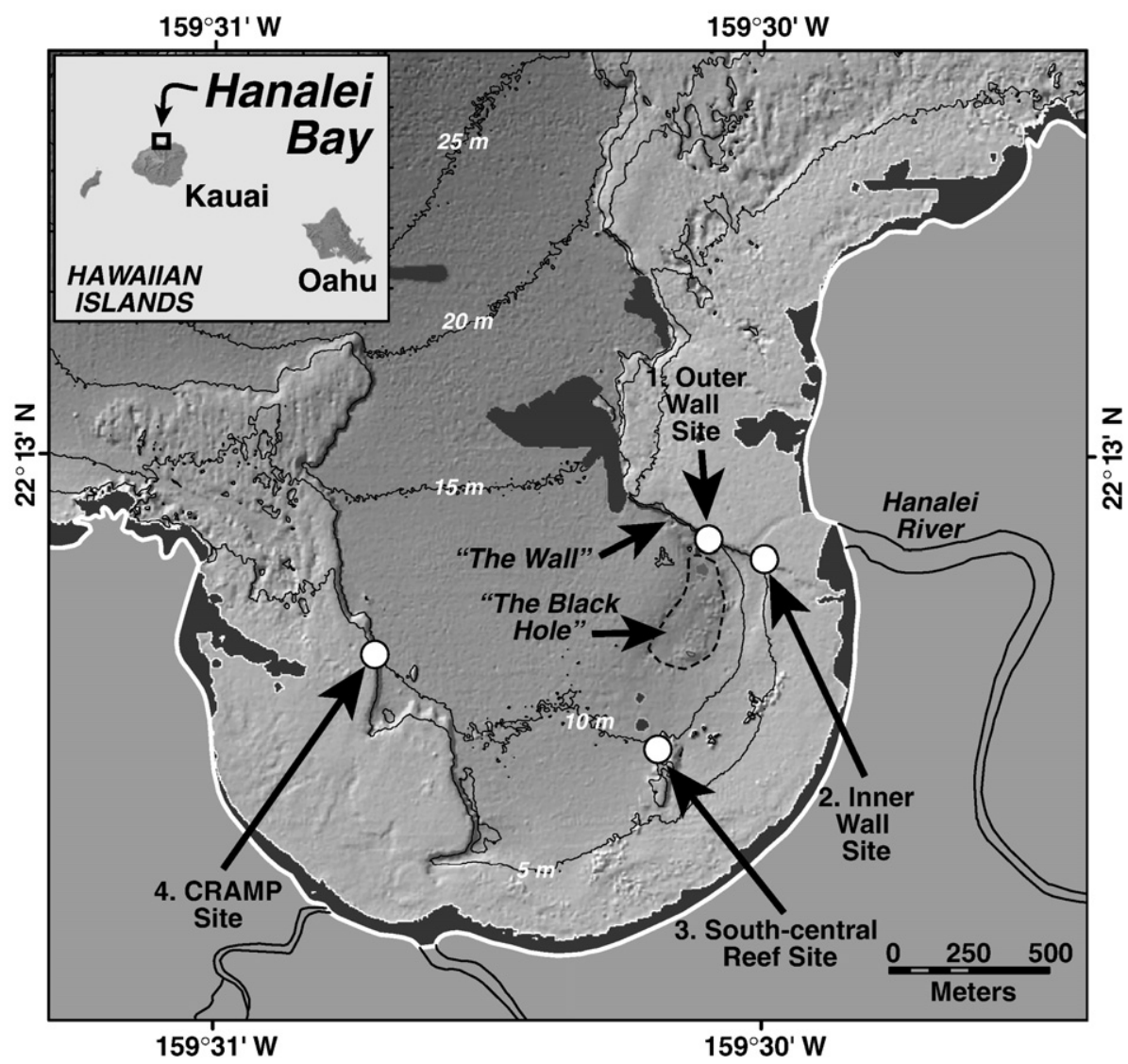

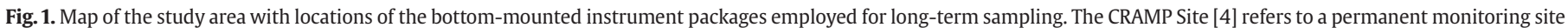

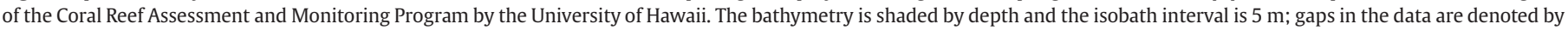
black regions. Inset: Location of the study area in relation to the main Hawaiian Island chain.

studies have shown the importance of the phasing between sediment delivery and oceanographic forcing (waves, currents, etc), differentiating between the effects of high suspended sediment concentrations (SSCs) in the water column due to wave resuspension versus those due to settling of a flood plume. Our study was designed to expand on their contributions and link the observed forcing and SSCs to seabed sediment dynamics and identify the long-term effects of the floods on benthic coral communities. Systematic studies that couple hydrologic, oceanographic, and geologic data on the fluvial delivery, deposition, and persistence of terrestrial sediment are needed to better understand the complete impact of river floods on coral reef environments.

The goal of this study was to better understand the sediment dynamics in a coral reef-lined embayment influenced by ocean surface waves and river floods, and quantify the processes controlling sediment residence time and dispersal. Four fixed instrument packages were deployed to make in situ time-series measurements of waves, winds, currents, and sediment dynamics. These data were supplemented by sediment sampling to provide information on spatial variability in sediment physical and chemical properties. The measurements document the complex interactions between waves, tides, mean currents, and river floods that drive sediment dynamics in a reef-lined embayment and these processes' contributions to suspended sediment concentrations (SSCs) and net sedimentation. The implications of these results for coral reef health and the application of sediment traps to coral reef studies will also be addressed.

\section{Study area}

This study focused on sediment dynamics in Hanalei Bay, an embayment approximately $4.4 \mathrm{~km}^{2}$ on the north shore of the island of
Kauai, Hawaii, USA. (Fig. 1). The floor of Hanalei Bay consists of marine carbonate sediment mixed with siliciclastic material derived from the basaltic highlands of the Hanalei River basin (Calhoun et al., 2002). The center of the bay is largely free of coral reef substrate, with a relatively flat sandy sea floor at a depth of approximately $10 \mathrm{~m}$. In the eastern portion of the bay, approximately $500 \mathrm{~m}$ from the river mouth, there is a broad (200-400 m wide) depression 2 to $5 \mathrm{~m}$ deep (water depth $\sim 12-$ $15 \mathrm{~m}$ ) known locally as the "Black Hole" because dark, fine-grained, organic-rich suspended sediment often obscures visibility; the seabed throughout the rest of the bay is primarily fine to medium sand (Calhoun and Fletcher, 1999; DeFelice and Parrish, 2001).

The physical environment offshore of the bay during the summer is dominated by northeasterly trade winds that generate wave heights of 1 to $3 \mathrm{~m}$ with periods of 5 to $8 \mathrm{~s}$ (Moberly and Chamberlain, 1964). Winter conditions, typically beginning in October and extending through March, are characterized by North Pacific swell that produces wave heights of 3 to $6 \mathrm{~m}$ with periods of 10 to $18 \mathrm{~s}$ that approach the bay generally from the northwest. The bay has a mixed, semi-diurnal microtidal regime, with the mean daily tidal range approximately $0.6 \mathrm{~m}$ and the minimum and maximum daily tidal ranges are $0.4 \mathrm{~m}$ and $0.9 \mathrm{~m}$, respectively; circulation is generally sluggish, with mean current speeds on the order of $0.02 \pm 0.02 \mathrm{~m} / \mathrm{s}$ (Storlazzi et al., 2006). The fringing reefs that line Hanalei Bay's eastern and western sides range in depth from $3 \mathrm{~m}$ to $20 \mathrm{~m}$ and host coral communities that are considered relatively healthy (Friedlander et al., 1997, 2005).

The $25 \mathrm{~km}$-long Hanalei River, one of the largest rivers in the Hawaiian Islands in terms of water discharge, drains an area of $54.4 \mathrm{~km}^{2}$ before flowing into the eastern corner of Hanalei Bay. Its north-facing drainage basin consists of steep-walled, heavily vegetated volcanic ridges and fluvial gorges that drain the island's $1500 \mathrm{~m}$ high central mountains, where rainfall commonly exceeds $10 \mathrm{~m} / \mathrm{yr}$. 
Table 1

Sensor and sediment trap deployment information.

\begin{tabular}{lll}
\hline Site name & Water depth & Sensors \\
\cline { 2 - 3 } & $(\mathrm{m})$ & \\
\hline Outer wall [1] & 10 & 600 kHz Acoustic Doppler current profiler (ADCP) \\
& 10 & Optical Backscatter Sensor (OBS) \\
& 10 & Conductivity-temperature sensor (CT) \\
& 10 & Coral Imaging System (CIS) \\
& 10 & Rotating Sediment Trap (RST) \\
& 3 & Conductivity-temperature sensor (CT) \\
& 3 & Optical Backscatter Sensor (OBS) \\
& 10 & Simple Tube Trap (STT) \\
Inner wall [2] & 9 & Simple Tube Trap (STT) \\
& 6 & 2 MHz Acoustic Doppler profiler (ADP) \\
& 6 & Optical Backscatter Sensor (OBS) \\
& 6 & Conductivity-temperature sensor (CT) \\
& 2 & Optical Backscatter Sensor (OBS) \\
& 2 & Conductivity-temperature sensor (CT) \\
[3] & 6 & Simple Tube Trap (STT) \\
& 10 & 2 MHz Acoustic Doppler profiler (ADP) \\
& 10 & Optical Backscatter Sensor (OBS) \\
& 10 & Conductivity-temperature sensor (CT) \\
& 10 & Rotating Sediment Trap (RST) \\
& 10 & Simple Tube Trap (STT) \\
& 9 & Simple Tube Trap (STT) \\
CRAMP Site [4] & 10 & 600 kHz Acoustic Doppler current profiler (ADCP) \\
& 10 & Optical Backscatter Sensor (OBS) \\
& 10 & Conductivity-temperature sensor (CT) \\
& 10 & Simple Tube Trap (STT) \\
\hline
\end{tabular}

Numbers in brackets refer to site locations on Fig. 1.

The steep topography of the drainage basin and heavy precipitation cause frequent landslides that deliver approximately $1.76 \times 10^{4} \mathrm{Mg}$ of sediment annually to the Hanalei River, with approximately $70 \%$ of this annual fluvial sediment load being delivered to the bay (Calhoun and Fletcher, 1999). The river's daily mean discharge, suspended sediment concentration, and suspended sediment load is $11 \pm 86 \mathrm{~m}^{3} / \mathrm{s}, 14 \pm$ $3 \mathrm{mg} / \mathrm{l}$, and $62 \pm 39 \mathrm{MT}$, respectively. Two small perennial streams and several smaller intermittent streams discharge into the bay's south and west sides. While it rains throughout the year, the heaviest rains and greatest discharges occur during the winter months (Pacific Islands Water Science Center, 2006). Although infrequent, small summer floods sometimes do occur, they deliver sediment loads an order of a magnitude less than most winter floods (Draut et al., 2009).

Cochran et al. (2007) collected short $(\sim 5 \mathrm{~cm})$ surficial sediment cores in June and September, 2006, at 11 sites in the bay to provide relative proportions, by mass, of sand and mud in each sample. Draut et al. $(2006,2008)$ concurrently collected 30 to $50 \mathrm{~cm}$-long sediment cores with a diver-operated hand-held coring unit at 9 of the sites sampled by Cochran et al. (2007) for detailed sedimentological and geochemical analyses. Clear evidence of new terrestrial sediment accumulation in the seabed between June and September, 2006, was documented in the cores collected in the Black Hole; however, little indication of new sediment was observed in cores collected elsewhere in the bay.

\section{Field experiment and methods}

\subsection{Hydrologic and oceanographic data}

Instruments were deployed at four locations in Hanalei Bay to collect in situ time-series measurements of waves, flow, and water column properties (Fig. 1, Table 1); all of the sites were at a depth of $10 \mathrm{~m}$, except for the Inner Wall Site, which was at $6 \mathrm{~m}$. These instruments included two $600 \mathrm{kHz}$ upward-looking acoustic Doppler current profilers (ADCPs), two $2 \mathrm{MHz}$ upward-looking ADCPs, 4 optical backscatter sensors (OBSs), and 4 conductivity-temperature sensors (CTs). An additional OBS and CT sensor was deployed on subsurface moorings at the Outer Wall and Inner Wall Sites, approximately even with the top of the reef flat at their respective locations. The ADCPs collected vertical profiles of current speed and direction, which in conjunction with the recorded pressure data, were used to calculate wave height, wave period, and wave direction. As part of the analyses, the ADCPs' current data were 10-28 h band-pass filtered to investigate the contribution of the tides to flow patterns and 36 hour low-pass filtered to look at the influence of winds and waves. The OBSs and CTs collected measurements of turbidity, and temperature and salinity, respectively, at specific depths. The ADCPs provided directional wave information every $2 \mathrm{~h}$; the ADCPs, OBSs, and CTs recorded water depth, current profiles, acoustic backscatter profiles, optical backscatter, temperature, and salinity data, respectively, every 5 min. The OBSs were calibrated to suspended sediment concentrations (SSCs) in units of mass per volume using surficial suspended sediment samples from the instrument sites collected in the field via scuba at the time of deployment.

The USGS Coral Imaging System (CIS) was deployed to provide timeseries data on the frequency and duration of sediment deposition and resuspension on an actual coral surface at the base of the reef. The CIS consists of a 6.3 megapixel digital camera with a $24 \mathrm{~mm}$ lens, an external TTL strobe, control unit and batteries on a tetrapod. The CIS was deployed $1.0 \mathrm{~m}$ above the sea bed in a patch of sand at the Outer Wall Site (Fig. 1, Table 1) and the camera and strobe were angled to image both live colonies of the coral Montipora capitata on the adjacent reef wall and a strategically placed black and white camera calibration reference block approximately $1.5 \mathrm{~m}$ away. The CIS took images every $4 \mathrm{~h}$ throughout the deployment (01:00, 05:00, 09:00, 13:00, 17:00 and 21:00 Hawaiian Standard Time). See Storlazzi et al. (2008) for more information on the instrument specifics, sampling schemes, and data processing.

Offshore meteorologic and wave conditions are monitored continuously by the National Data Buoy Center (2006) Northwest Hawaii buoy \#51001 that is deployed in $3 \mathrm{~km}$ of water approximately $270 \mathrm{~km}$ WNW of the island. In order to acquire local meteorologic data, a selfcontained weather station was deployed $3 \mathrm{~km}$ east of the bay to collect
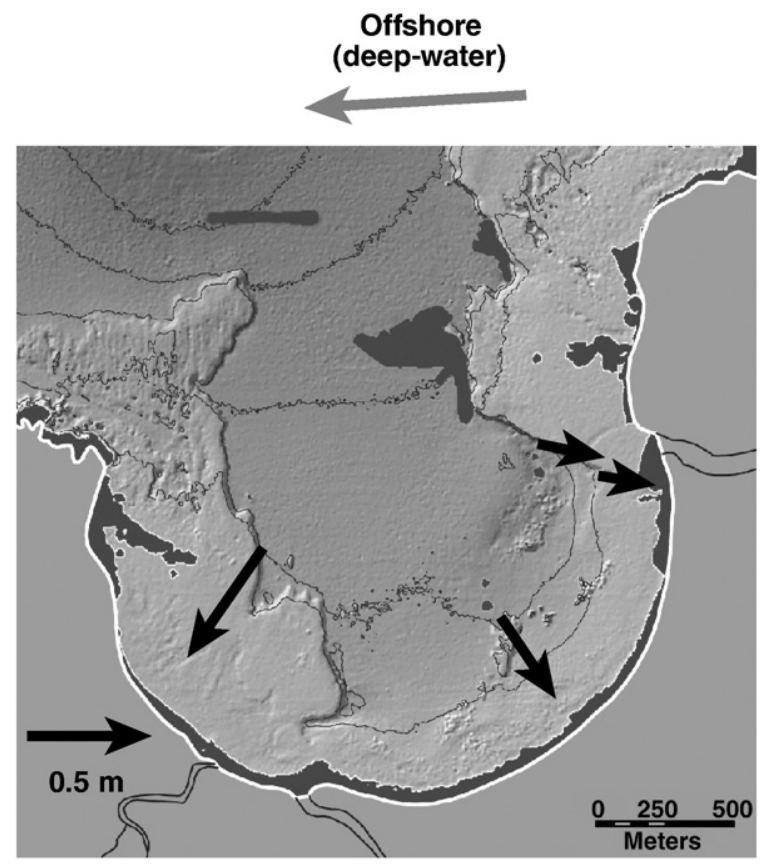

Fig. 2. Vectors denoting the mean wave height and direction at the four main sites during the study period. The grey vector shows the offshore, deep-water mean wave height and direction during the study (NDBC, 2006). The waves were larger in the more exposed western portion of the bay at the CRAMP Site and smaller off the Hanalei River's mouth at the Inner Wall Site. 
wind speed, wind direction, barometric pressure, air temperature, and rainfall data, with each parameter averaged over 25 min and recorded every half hour. Water discharge and suspended sediment concentration data for the Hanalei River are measured by the Pacific Islands Water Science Center (2006) gauging station \#16103000, located approximately $9 \mathrm{~km}$ upstream from the river mouth.

\subsection{Sediment collection}

Two types of sediment traps collected suspended sediment from the water column in the bay. Simple tube traps (STT), consisting of a clear plastic tube $30 \mathrm{~cm}$ long with an internal diameter of $6.7 \mathrm{~cm}$, were deployed with their openings $0.4 \mathrm{~m}$ above the seabed at the four main instrument sites (Fig. 1, Table 1). An additional STT was deployed with its opening $1.4 \mathrm{~m}$ above the seabed at the Outer Wall and South-central Reef Sites to evaluate vertical gradients in trap collection rates. A baffle was placed in the top of each tube trap to reduce turbulence and minimize disturbance by aquatic organisms (Bothner et al., 2006). Programmable rotating sediment traps (RST), modified after McLane Research Laboratories (2004), were deployed with their openings $1.4 \mathrm{~m}$ above the seabed at the Outer Wall and South-central Reef Sites. Each rotating trap consisted of a $20 \mathrm{~cm}$-internal-diameter, a $75 \mathrm{~cm}$-long cylinder equipped with a funnel in the lower $15 \mathrm{~cm}$ of the cylinder to direct settling sediment into one of the 21 plastic bottles ( $500 \mathrm{ml}$ ). Sampling a)

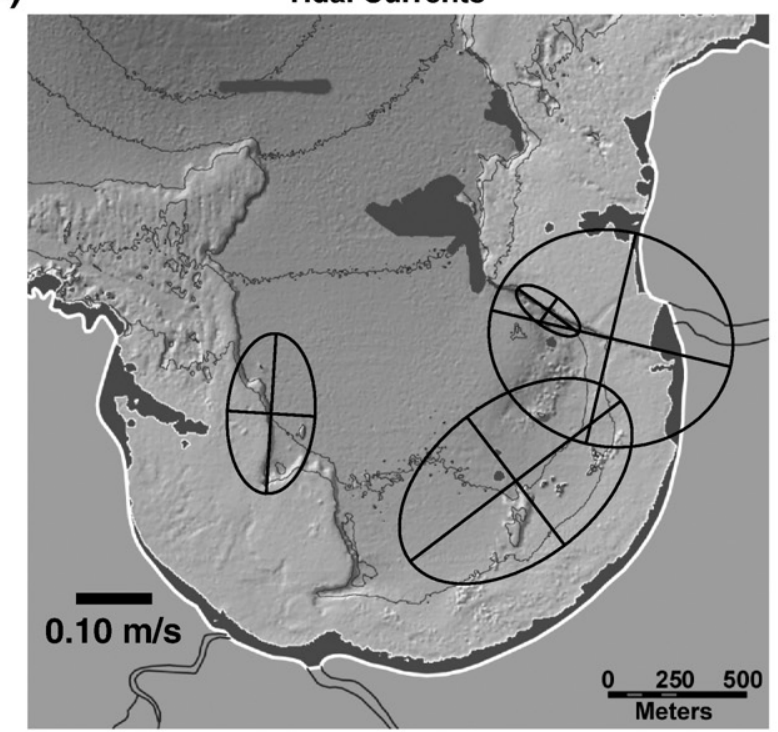

c)

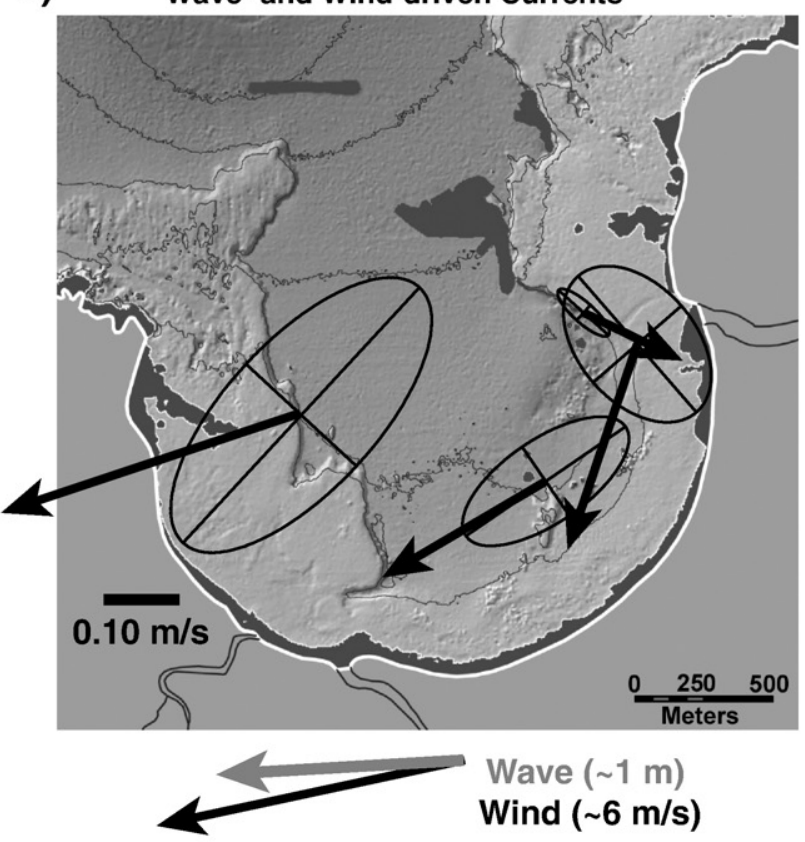

d)

b)

\section{Near-Bed} Tidal Currents

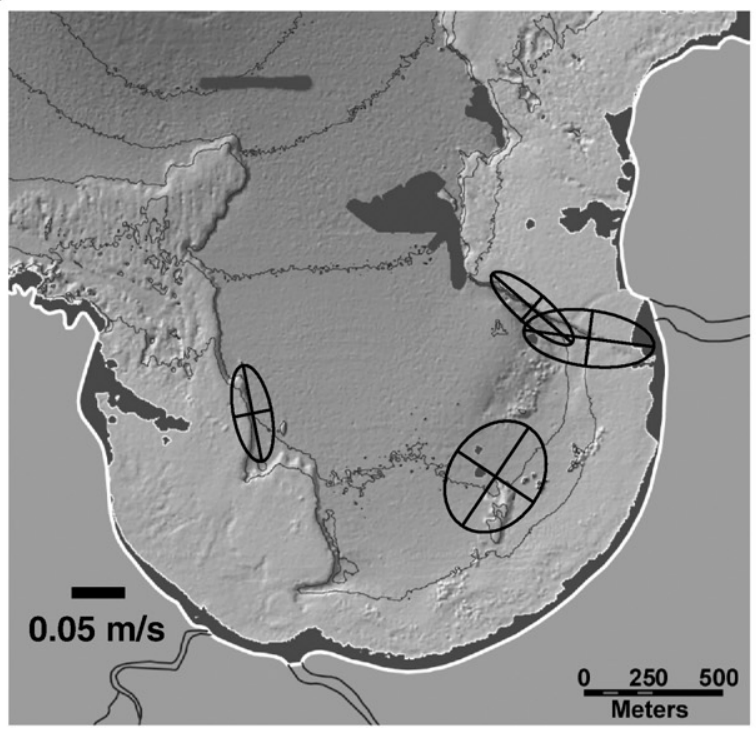

Near-Bed

Near-Surface

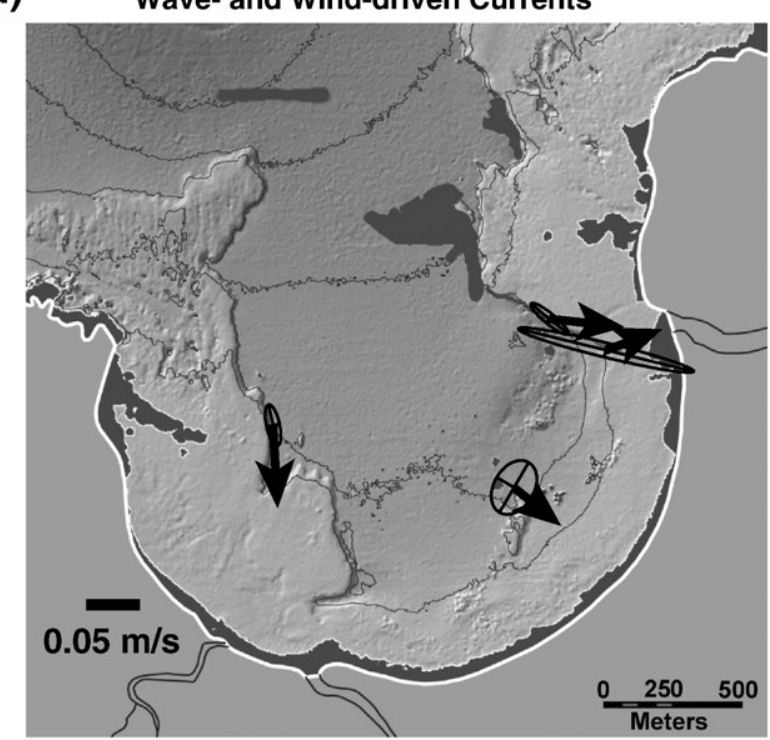

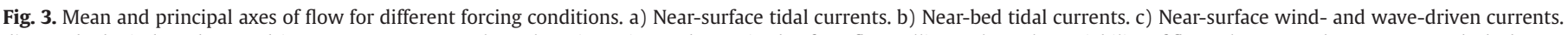

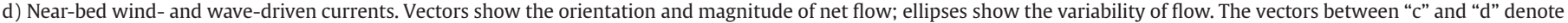

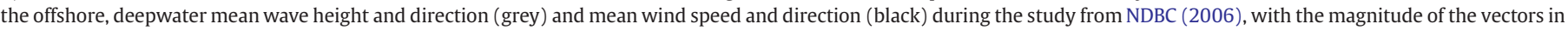

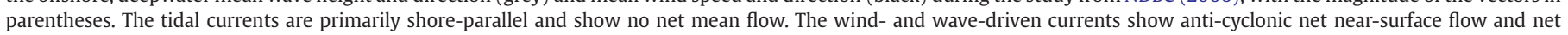
onshore flow near the seabed. 
Table 2

Data statistics for the four study sites.

\begin{tabular}{|c|c|c|c|c|}
\hline Site name & Outer wall [1] & Inner wall [2] & South-central reef [3] & CRAMP [4] \\
\hline Mean combined wave-current near-bed shear stress $\left(\mathrm{N} / \mathrm{m}^{2}\right)$ & $0.01 \pm 0.02$ & $0.03 \pm 0.10$ & $0.06 \pm 0.07$ & $0.13 \pm 0.07$ \\
\hline Mean near-bed suspended sediment concentration (mg/l) & $2.81 \pm 2.66$ & $2.77 \pm 2.34$ & $3.08 \pm 6.22$ & $1.79 \pm 1.84$ \\
\hline Mean near-surface suspended sediment concentration (mg/l) & $1.68 \pm 1.44$ & $0.93 \pm 0.68$ & - & - \\
\hline STT trap accumulation rate $\left(\mathrm{g} / \mathrm{m}^{2} /\right.$ day $) 0.4 \mathrm{~m}$ above the bed & 177 & 213 & 636 & 433 \\
\hline STT trap accumulation rate $\left(\mathrm{g} / \mathrm{m}^{2} /\right.$ day $) 1.4 \mathrm{~m}$ above the bed & 70 & 47 & - & - \\
\hline Terrigenous in sand fraction of STT (\%) & 67.05 & 51.13 & 28.01 & 30.03 \\
\hline Terrigenous in mud fraction of STT (\%) & 92.28 & 91.26 & 63.53 & 53.83 \\
\hline Organic carbon in sand fraction of STT (\%) & 8.89 & 4.75 & 1.47 & 2.30 \\
\hline Organic carbon in mud fraction of STT (\%) & 4.61 & 8.08 & 2.76 & 2.44 \\
\hline
\end{tabular}

Numbers in brackets refer to site locations on Fig. 1.

The sand and mud fractions are defined as those $>63 \mu \mathrm{m}$ and $<63 \mu \mathrm{m}$, respectively.

bottles were mounted on a carousel that rotated a new bottle under the funnel every 4.4 days. Both types of sediment traps were employed in this study to obtain a relative measure of suspended sediment collection rates and sufficient quantity of suspended material for physical and chemical characterization. Because of the energetics of the insular shelf environment, the traps did not measure net vertical sediment flux to the coral reef surface. This is because material falling into the trap has a much lower potential for resuspension than the same material that settles on the adjacent reef surface (Bothner et al., 2006). In addition, the traps were likely to preferentially collect coarser particle sizes because of their higher settling velocity than finer particles. Particles with slow settling velocities relative to the circulation and exchange of water contained in the trap can be underrepresented in the collected samples (e.g., Gardner et al., 1983; Baker et al., 1988). The average daily trap collection rate for both the STTs and RSTs was calculated by measuring the total mass of sediment in the trap or bottle and dividing by the trap cross-sectional area and the duration of collection period.

The relatively small volumes of sediment collected in some of the RST bottles were due to their short (4.4 day) sampling intervals, thus sediment grain size and composition analyses were only made on select RST samples with sufficient sample volume; all of the STT samples contained enough sample material to be processed. Sediment grain size analysis was conducted on wet aliquots of the trap samples using sieving and Coulter Counter techniques described by Poppe et al. (2000). Total carbon and carbonate carbon measurements were made using a Perkin Elmer CHN analyzer and a UIC coulometer, respectively. Organic carbon (C) was determined by the difference between total carbon and carbonate carbon. Critical shear stresses for the different types of sediment were calculated using the modified Shield parameter methodology of Madsen (1999).

\section{Results}

\subsection{Prevailing hydrographic conditions}

The in situ instruments recorded data for a 90-day period from June 7 through September 5, 2006 (Year Day [YD] 158-248). During the northeast trade-wind conditions that characterize the Hawaiian Islands' summer, the mean offshore wind speed and direction was $6.5 \mathrm{~m} / \mathrm{s}$ from $76^{\circ}$, and deep-water wave heights were on the order of 0.74 to $3.10 \mathrm{~m}$ at 5 to $19 \mathrm{~s}$ (mean \pm 1 standard deviation of $1.85 \pm 0.43 \mathrm{~m}$ and $9 \pm 2 \mathrm{~s}$, respectively) from $87^{\circ}$. Due to shoaling and refraction around the bay's eastern headland, the wave heights and periods in the bay ranged between 0.05 and $1.36 \mathrm{~m}$ at 3 to $5 \mathrm{~s}$, with the waves being larger in the more exposed western portion of the bay at the CRAMP Site $(0.51 \pm$ $0.11 \mathrm{~m}$ ) and smaller off the Hanalei River's mouth at the Inner Wall Site $(0.14 \pm 0.03 \mathrm{~m})$, as shown in Fig. 2 .

While most of the daily variability in current speed and direction in the study area was due to the tides, the low tidal range resulted in relatively weak tidal currents in the bay, with mean tidal current speeds ranging from 0.01 to $0.02 \mathrm{~m} / \mathrm{s}$ close to the seabed and 0.03 to $0.12 \mathrm{~m} / \mathrm{s}$ close to the surface. The principal axes of tidal flow during the experiment were oriented roughly parallel to the local isobaths and showed no asymmetry; the orientation of tidal flow ellipses was more variable close to the surface and in the relatively flat southern portion of the bay (Fig. 3a,b). Similar to the tidal currents, the principal axes of low-frequency wave- and wind-driven currents near the surface were oriented relatively parallel to the local isobaths; these currents, however, showed strong net anti-cyclonic (or clockwise) flow (Fig. 3c). The major axes of the wave- and wind-driven current ellipses near the bed were oriented sub-parallel to the local isobaths and were smaller than near the surface. Near-bed net waveand wind-driven flows were all oriented approximately shoreward into the bay (Fig. 3d), similar in orientation to the mean wave vectors displayed in Fig. 2.

The total shear stresses imparted on the seabed, computed from the wave and mean near-bed current data using the methodology

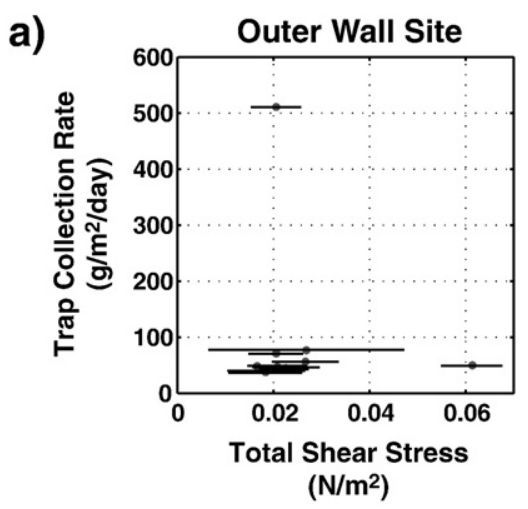

b)

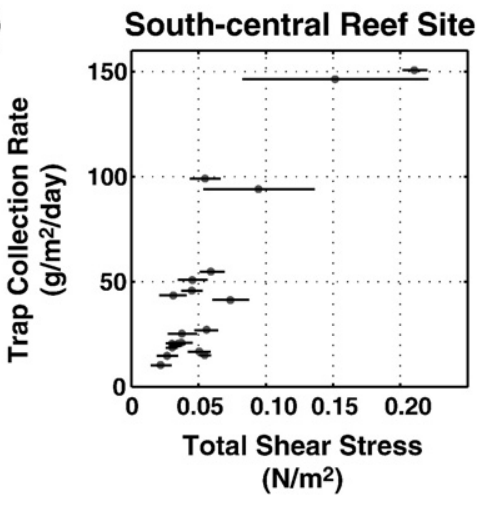

Fig. 4. Rotary sediment trap (RST) collection rates as a function of combined wavecurrent near-bed shear stresses. a) Data from the Outer Wall Site. b) Data from the South-central Reef Site. The variation in the Outer Wall Site's RST collection rate showed no relationship with total shear stress, suggesting the material collected was advected to the site. The variation in the South-central Reef Site's RST collection rate displayed a statistically significant relationship with shear stress, suggesting the material collected was, in part, resuspended from the surrounding seabed. 
a)

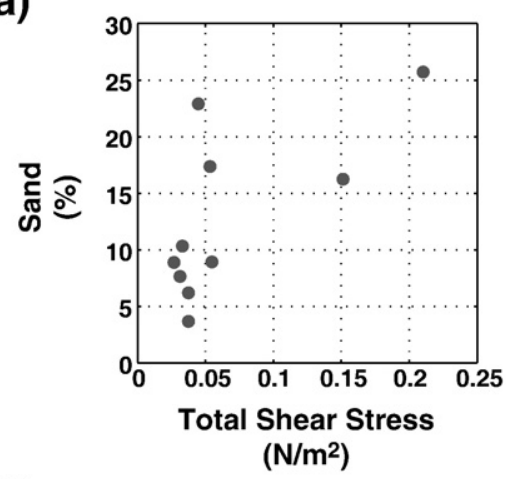

b)

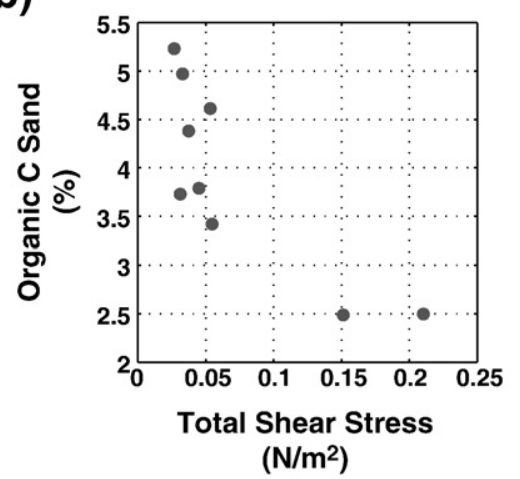

d)

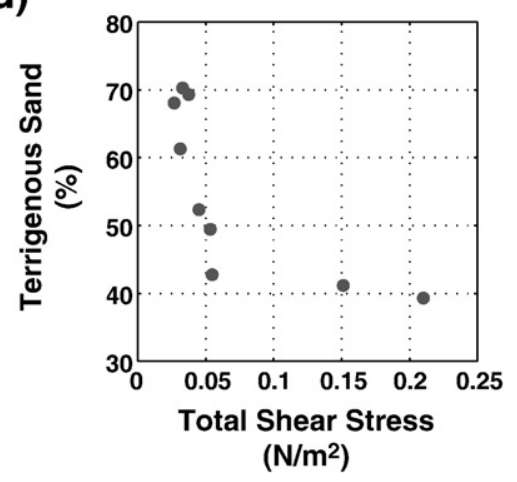

c)

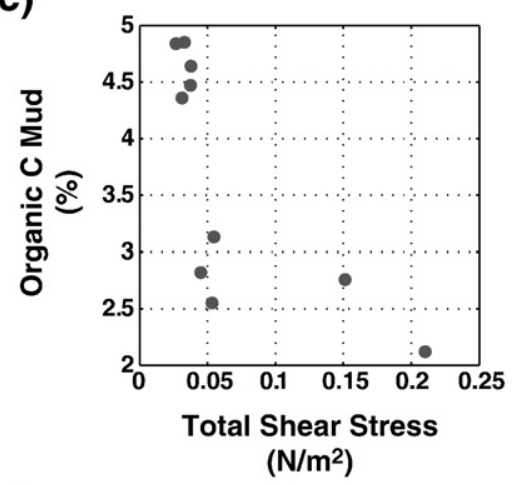

e)

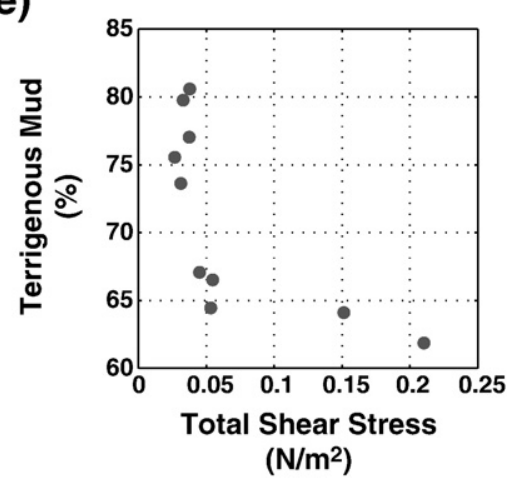

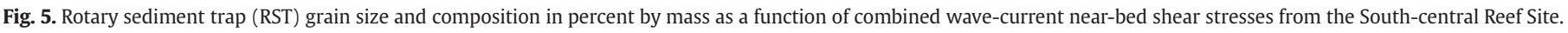

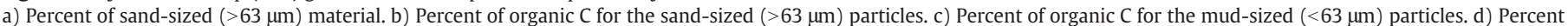

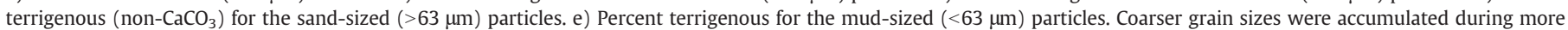

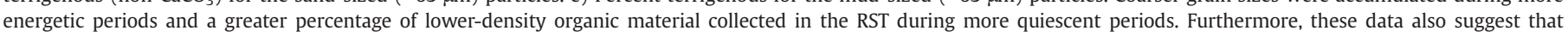

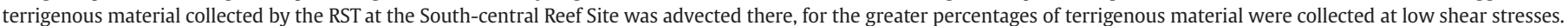

presented by Ogston et al. (2004), were dominated by wave-orbital motions. This resulted in a pattern of near-bed shear stress during the experiment (Table 2) similar to the distribution of waves (Fig. 2), with the largest total shear stresses in the more exposed western portion of the bay at the CRAMP Site and smaller in the eastern portion of the bay, with lowest values at the Outer Wall Site. Even though the waves were smaller, the total shear stress was slightly higher and much more variable at the Inner Wall Site than the Outer Wall Site due to its shallower ( $6 \mathrm{~m}$ vs. $10 \mathrm{~m}$ ) water depth.

Overall, suspended sediment concentrations (SSCs) in Hanalei Bay were low during the summer of 2006, with the exception of largerthan-normal wave events and a river flood. Mean SSCs calculated from the OBS measurements were smallest and least variable near the surface at the Inner Wall Site and highest at the South-central Reef Site (Table 2). In general, the mean near-bed SSCs throughout the bay were twice as high and more variable than mean near-surface SSCs at the Outer and Inner Wall Sites. Although a seasonal warming trend and tidally driven variations in temperature were observed in the CT time series (not shown), pulses in stream flow, groundwater discharge (which were often visible during scuba diving operations), and false conductivity readings (likely due to sediment clogging the sensors) made the salinity data difficult to interpret.

\subsection{Sediment trap samples}

The mean daily trap collection rates measured in the simple tube traps (STTs) deployed at the four main study sites for just over 90 days between June 6 and September 7, 2006, was $365 \pm 213 \mathrm{~g} / \mathrm{m}^{2} /$ day (Table 2). The highest trap collection rates were in the more energetic western and southern portions of the bay and lowest in the quiescent northeastern portion of the bay off the Hanalei River mouth. The STTs with openings at $0.4 \mathrm{~m}$ above bottom at the Outer Wall and Southcentral Reef sites collected 2.5 and 13.5 times, respectively, more sediment than the co-located STTs with their openings $1.4 \mathrm{~m}$ above bottom. The composition and grain size of the material in the four STTs varied spatially (Table 2). The highest terrigenous values in both size 

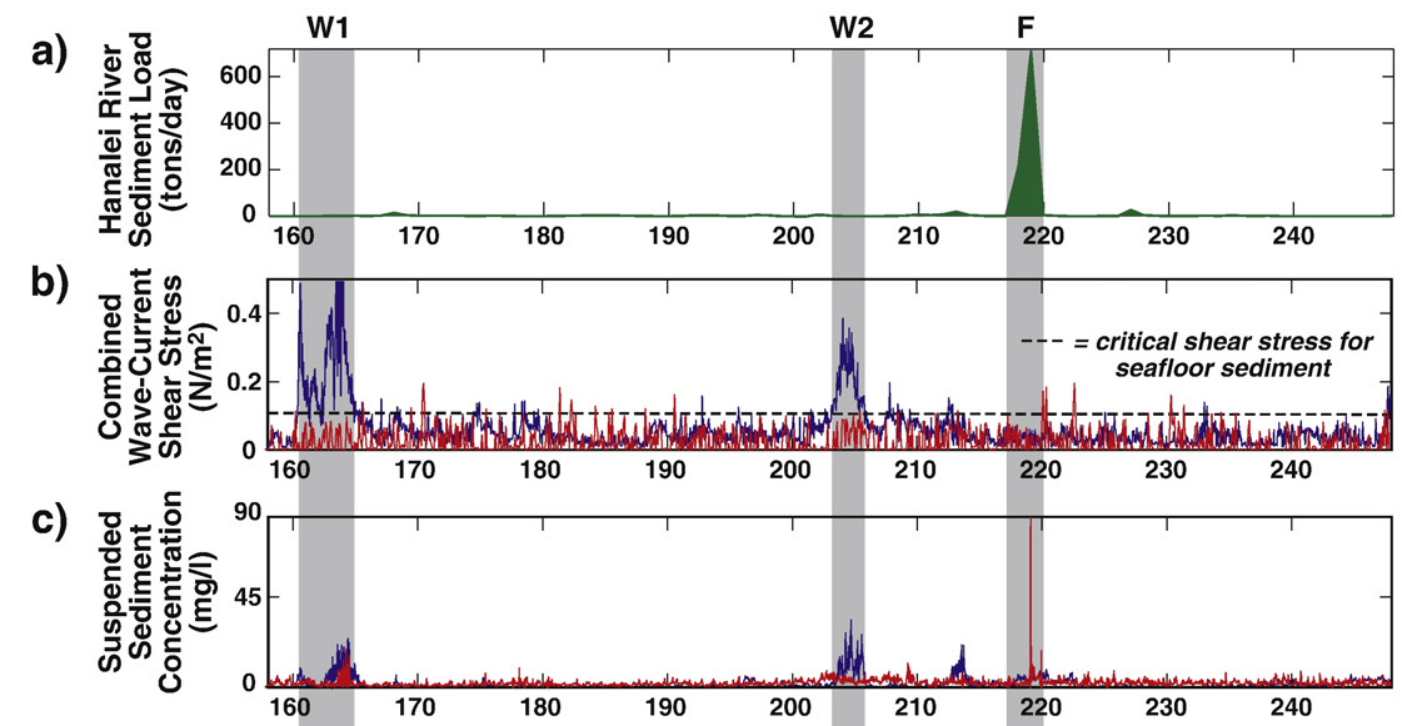

d)

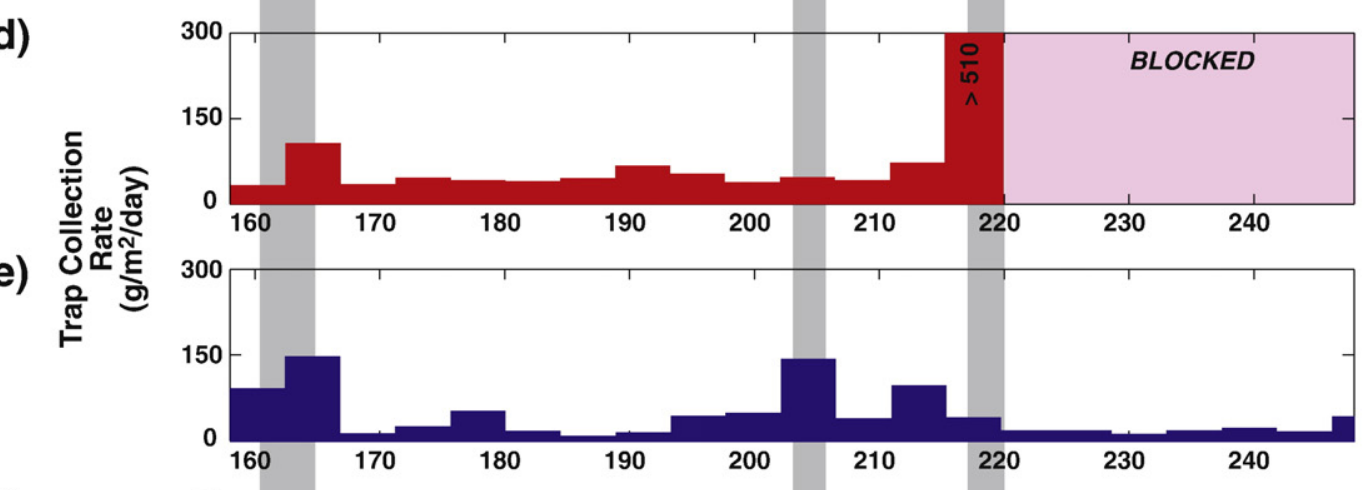

f)

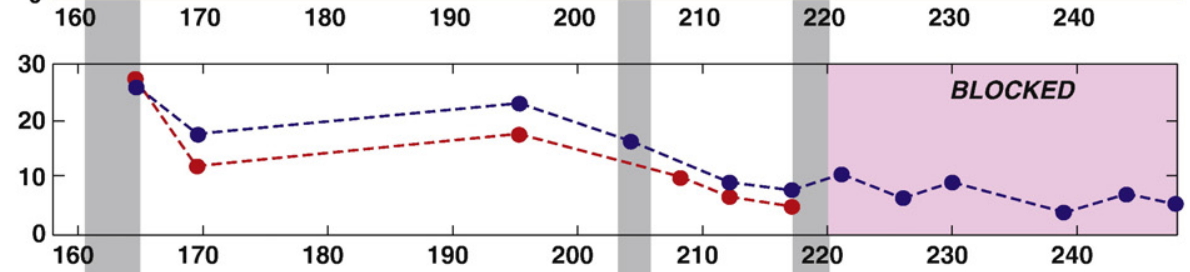

g)
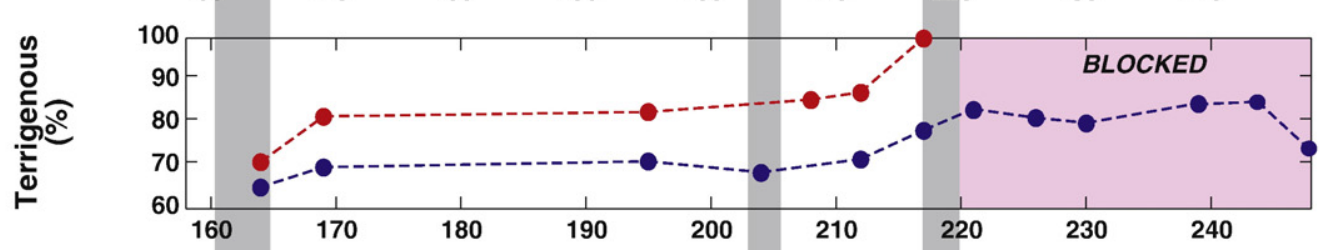

h)

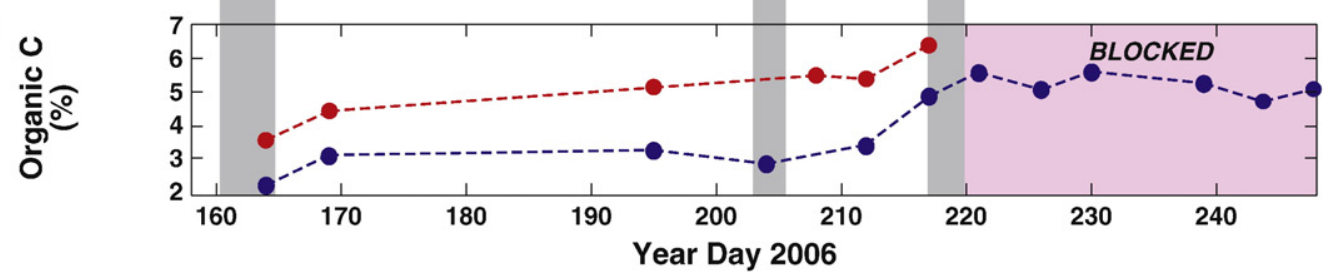

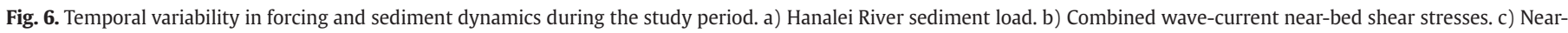

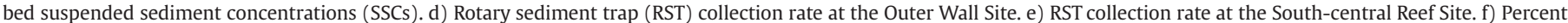

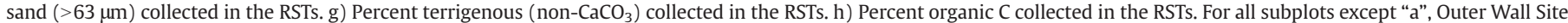

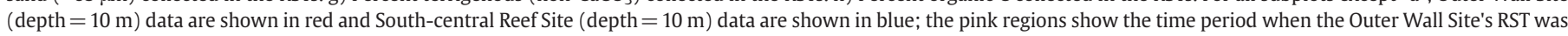

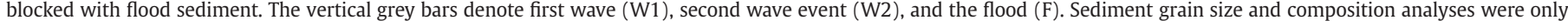
made on select RST samples with sufficient sample volume.

fractions were found off the Hanalei River mouth at the Outer and Inner Wall Sites and the lowest at the CRAMP Site; the highest percentages of organic $C$ in both the mud and sand were recorded off the Hanalei River mouth, and the lowest values were recorded at the CRAMP Site.
The average daily rotary sediment trap (RST) collection rate, calculated by measuring the total mass of sediment collected in each bottle and dividing by the cross-sectional area of the collection funnel and the time under the collection funnel, was $87 \pm 123 \mathrm{~g} / \mathrm{m}^{2} / \mathrm{d}$ (including the overflowed flood sample) and $47 \pm 43 \mathrm{~g} / \mathrm{m}^{2} / \mathrm{d}$ for the 
a)

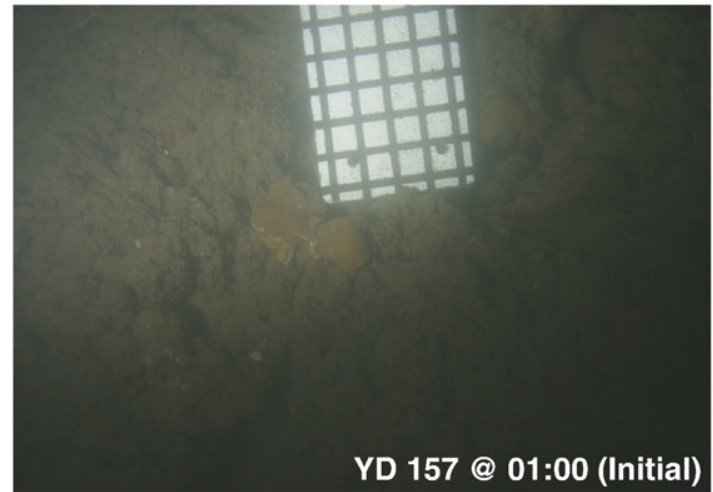

b)

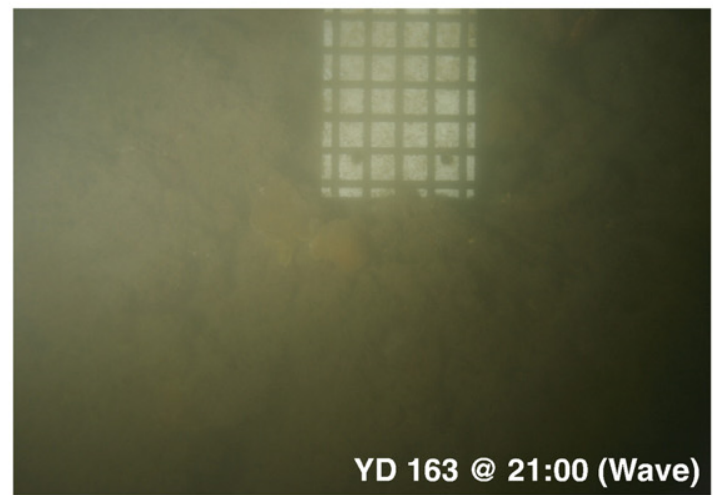

c)

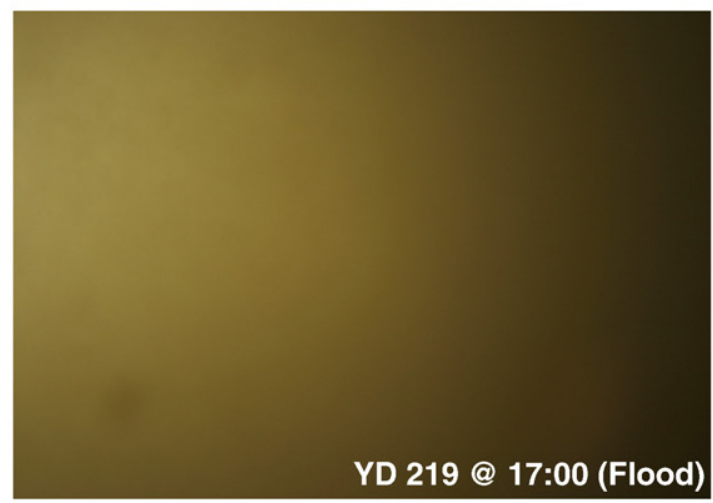

d)

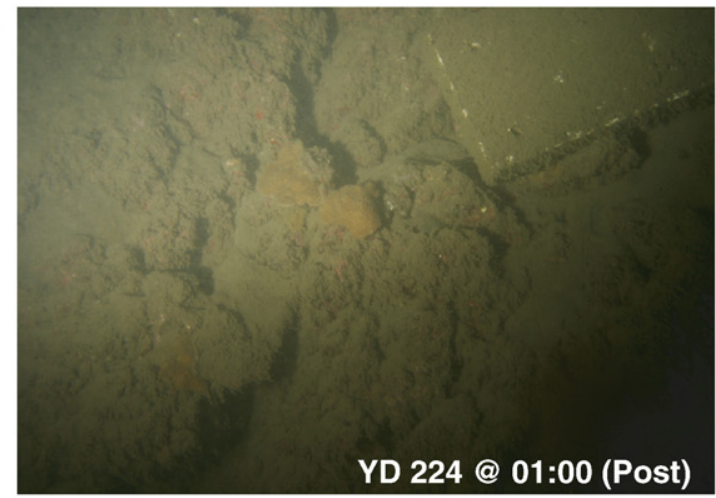

Fig. 7. Time series of images of the reef along the Outer Wall Site from the Coral Imaging System (CIS). a) Relatively clear water and some fine-grained sediment on the fore reef at the beginning of the study period. b) Higher turbidity during the first large wave event from the northwest in early June (YD 161-165). c) The $46 \mathrm{~m}^{3} / \mathrm{s}$ Hanalei River flood that delivered 771 MT of sediment to the bay on August 6-7 (YD 218-219) resulted in $24 \mathrm{~h}$ of complete "brown-out" along the Outer Wall. Also note the more reddish color of terrigenous material compared to the wave event in "b". d) Following the flood, all of the potential coral recruitment sites remained buried for the rest of the study. The field of view is approximately $1 \mathrm{~m}$.
Outer Wall and South-central Reef Sites, respectively. While the variation in the Outer Wall Site's RST collection rate through time showed no relationship $\left(r^{2}=0.02\right)$ with total shear stress (Fig. 4a), the variation in the South-central Reef Site's RST collection rate through time displayed a statistically significant $\left(r^{2}=0.77, n=21\right.$, $p=0.001$ ) correlation with shear stress (Fig. 4b), similar to the strong power-law relationship found between these parameters off the island of Molokai during 2002 and 2003 (Bothner and Storlazzi, unpublished data). Coarser grain sizes were collected by the Southcentral Reef Site's RST during more energetic periods (Fig. 5a), and a greater percentage of lower-density organic material collected during more quiescent periods (Fig. 5b-c). Furthermore, this RST collected greater percentages of terrigenous material at low shear stresses than at higher stresses (Fig. 5d-e). There are no significant relationships, however, between total shear stress, river sediment load, and sediment grain size and composition at the Outer Wall Site (not shown).

\subsection{Temporal variability in forcing and sediment dynamics}

While the study period was characterized by relatively constant northeast trade winds and trade-wind waves, it was punctuated by three significant events: two periods of larger-than-normal waves in early June (YD 161-165) and in late July (YD 202-205), and a Hanalei River flood on August 6-7 (YD 218-219), as shown in Fig. 6a,b. During time intervals between these events, combined wave-current near-bed shear stresses rarely exceeded the $0.10 \mathrm{~N} / \mathrm{m}^{2}$ resuspension threshold at both the Outer Wall and South-central Reef Sites. The exceptions (12 times, maximum duration $=4 \mathrm{~h}$ ) occurred when stronger-than-normal low-frequency currents caused near-bed shear stresses to just barely exceed the $0.10 \mathrm{~N} / \mathrm{m}^{2}$ threshold. The critical shear stress of $\sim 0.10 \mathrm{~N} / \mathrm{m}^{2}$ is consistent for both carbonate sand and terrigenous mud assuming $\rho_{\text {sed }} \sim 1.85 \mathrm{~g} / \mathrm{cm}^{3}$ and $2.65 \mathrm{~g} / \mathrm{cm}^{3}$, respectively. In the non-event periods, near-bed SSCs and RST collection rates were generally two times higher at the Outer Wall Site $\left(1.4 \pm 1.8 \mathrm{mg} / \mathrm{l}\right.$ and $50 \mathrm{~g} / \mathrm{m}^{2} /$ day $)$ than at the South-central Reef Site $\left(0.7 \pm 0.4 \mathrm{mg} / \mathrm{l}\right.$ and $28 \mathrm{~g} / \mathrm{m}^{2} /$ day $)$. Imagery from the CIS at the Outer Wall Site documented relatively clear water and some fine-grained sediment on the fore reef at the beginning of the study period (Fig. 7a).

\subsubsection{Wave-driven sediment dynamics}

During the first large wave event out of the northwest in early June (YD 161-165), the shear stresses at the more exposed South-central Reef Site exceeded $0.10 \mathrm{~N} / \mathrm{m}^{2}$ for more than 3 days ("W1", Fig. 6b). These high shear stresses coincided with more than an order of magnitude increase in near-bed SSCs (25.6 and $34.4 \mathrm{mg} / \mathrm{l}$; Fig. 6c) and a doubling of RST collection rates (108 and $152 \mathrm{~g} / \mathrm{m}^{2} /$ day; Fig. 6d-e) at the Outer Wall and South-central Reef Sites, respectively; the nearsurface SSC at the Outer Wall Site $(14.7 \mathrm{mg} / \mathrm{l})$ was also more than a magnitude higher during this event. Higher turbidity was imaged by the CIS (Fig. 7b) at the Outer Wall Site at this time, and the imagery suggests that this turbidity resulted from the resuspension of lightcolored or white, reef-derived carbonate material dissimilar to the predominantly dark-colored seabed (predominantly terrigenous) material found on the seabed at the site (Cochran et al., 2007). The CIS imagery showed that the SSCs at the Outer Wall Site $(\sim 20 \mathrm{mg} / \mathrm{l})$ resulted in an approximately $40 \%$ decrease in light penetration over a $1.5 \mathrm{~m}$ horizontal path length (the distance between the CIS and the Wall) $1 \mathrm{~m}$ above the seabed. While the instruments at the Outer Wall Site did not measure near-bed shear stresses exceeding the critical shear stress threshold of $0.10 \mathrm{~N} / \mathrm{m}^{2}$ during this event, it is likely that wave breaking over the reef flat just to the north of the site resuspended reef-derived carbonate material on the reef flat and transported it over into the deeper, more quiescent waters at the Outer Wall Site. The accumulation of coarse, calcareous-rich sediment in the Outer Wall Site RST during this time (Fig. 6f-g) supports the 
conjecture of off-reef transport. This sediment was likely responsible for the more than an order of magnitude increase in both near-surface and near-bed SSCs.

In late July (YD 202-205), the study area was impacted by a wave event that was smaller than the early June event but still generated combined wave-current near-bed shear stresses three times larger than typically observed at the South-central Reef Site ("W2", Fig. 6b). At this location, the $0.10 \mathrm{~N} / \mathrm{m}^{2}$ critical shear stress threshold was exceeded for more than $24 \mathrm{~h}$, SSCs greater than $43.5 \mathrm{mg} / \mathrm{l}$ were measured, RST collection rates were more than $149 \mathrm{~g} / \mathrm{m}^{2} /$ day, and the proportion of terrigenous sediment collected by the RST decreased slightly. The Outer Wall Site did not appear to be impacted by this event, with SSCs $(7.6 \mathrm{mg} / \mathrm{l})$ and RST collection rates $\left(50 \mathrm{~g} / \mathrm{m}^{2} /\right.$ day $)$ on the order of those measured during non-event periods; these SSCs resulted in an approximately $15 \%$ decrease in near-bed light penetration at the CIS. The different response in terms of SSCs and RST collection rates at the two sites was probably due to the event's smaller wave heights and more northerly wave approach (rather than the northwesterly wave approach during the early June event), which resulted in lower overall wave energy and likely caused more wave energy to be dissipated on the reef flat to the north of the Outer Wall Site.

\subsubsection{Flood sediment dynamics}

On August 6-7 (YD 218-219), a $46 \mathrm{~m}^{3} / \mathrm{s}$ Hanalei River flood delivered 771 MT of sediment to the bay ("F", Fig. 6a), roughly an order of magnitude greater sediment load than during mean condition; SSCs in the river during the peak of the flood exceeded $90 \mathrm{mg} / \mathrm{l}$ approximately $9 \mathrm{~km}$ upstream from the river mouth (Pacific Islands Water Science Center, 2006). The combined wave-current near-bed shear stresses during this event remained below the critical shear stress of $0.10 \mathrm{~N} / \mathrm{m}^{2}$ (Fig. 6b). At the Inner Wall Site directly offshore the Hanalei River, the near-surface (depth $\sim 2 \mathrm{~m}$ ) and near-bed (depth $\sim 6 \mathrm{~m}$ ) SSCs were 63.3 and $86.7 \mathrm{mg} / \mathrm{l}$, respectively. At the Outer Wall Site farther offshore, the near-surface (depth $\sim 3 \mathrm{~m}$; not shown) and near-bed (depth $\sim 10 \mathrm{~m}$ ) OBSs were saturated during the flood by the high SSCs, signifying SSCs exceeded $90 \mathrm{mg} / \mathrm{l}$ throughout the water column at the site; the nearsurface SSCs stayed elevated above background levels for more than twice as long as those close to the seabed.

The RST sampling bottle in place during the flood period (bottle 14, Fig. 10d) overflowed with material that was up to $95 \%$ mud, up to $99 \%$ terrigenous, and contained up to $6.4 \%$ organic C (Fig. 6 h). The RST collection rate exceeded $510 \mathrm{~g} / \mathrm{m}^{2} /$ day, which exceeded the bottle volume within 4.5 days; this in turn resulted in clogging the funnel above the bottle and preventing sediment entry to the 6 bottles remaining in the time series. Sediment from the flood did not overflow the co-located STT, likely due to the greater ratio of volume to collection area in the STT. The flood resulted in $24 \mathrm{~h}$ of complete "brown-out" ( $0 \%$ light penetration) at this location as shown by the CIS imagery (Fig. 7c), followed by 3 days of elevated turbidity that caused near-bed light penetration to be reduced by more than $50 \%$. The red band in the CIS imagery was elevated relative to the blue and green bands in the red-green-blue color spectrum, which was not observed during the previous wave events, further supporting the observation of an influx of reddish, fine-grained terrestrial sediment. While the individual coral colonies appeared to survive the flood's sedimentary load, as evidenced by their relatively fast sloughing off the mud, all of the potential recruitment sites remained buried for the rest of the study period (Fig. 7d). In contrast to the high SSCs and RST collection rate measured at the Outer Wall Site, those measured at the South-central Reef Site during the flood ( $13.7 \mathrm{mg} / \mathrm{l}$ and $44 \mathrm{~g} / \mathrm{m}^{2} /$ day) remained similar to the non-event periods. For about four weeks following the flood (YD 219-240), however, the RST at the Southcentral Reef Site collected more finer-grained terrigenous sediment having a relatively high percentage of organic C, an indication of floodderived material.

\section{Discussion}

\subsection{Controls on sediment dynamics}

The results presented here display how the complex morphology of coral reefs, which attain bathymetric slopes and hydrodynamic roughnesses much greater than seen along relatively linear sandy shorelines, can cause significant gradients in hydrodynamic forcing over relatively short spatial scales. These small spatial and temporal differences in hydrodynamic processes, in turn, can cause substantial variations in the deposition, residence time, resuspension, and advection of both reef-derived and fluvial sediment in a small coral reef embayment.

During the initial stages of the August flood, the OBS signals both near the surface and near the bed (Fig. 6c) at the Outer Wall Site were saturated, suggesting SSCs exceeding $90 \mathrm{mg} / 1$ throughout the $10 \mathrm{~m}$ deepwater column, and the CIS site experienced a "brown-out" (Fig. 7c) as light penetration decreased to less than $1.5 \mathrm{~m}$. At the same time, however, slightly lower SSCs were measured closer to shore at the Inner Wall Site approximately $200 \mathrm{~m}$ away, suggesting that the momentum of the flood discharge may have driven much of the flow directly offshore of the river's mouth towards the Outer Wall Site and partially bypassed the shallower Inner Wall Site that is farther alongshore to the south. The large $\left(>510 \mathrm{~g} / \mathrm{m}^{2} /\right.$ day) influx of organic-rich, fine-grained terrestrial material to Outer Wall Site's RST (Fig. 6f-h) that caused it to overflow the sampling bottle is consistent with the significant initial deposition of flood material on the seabed at the Outer Wall Site, as well as the colonized and un-colonized portions on the Wall, as documented by the CIS. The lack of significant relationships between total shear stress and sediment grain size and composition of the Outer Wall Site's RST samples (Fig. 4a) further supports that trap collection at the Wall Site was primarily controlled by material discharged from the Hanalei River. The nearly vertically uniform SSCs from the sites along the Wall indicate rapid sediment mixing throughout the water column and the potential for substantial effects on the bed.

The longer duration of high SSCs close to the surface at the Outer Wall Site than near the seabed suggests that the majority of the sediment load was discharged quickly, possibly forming both hyperpycnal and hypopycnal flows, followed by sustained hypopycnal flow that persisted for more than a day. Scuba divers working at the CRAMP site $1000 \mathrm{~m}$ across the bay just after the peak of the August flood event noted that a plume of turbid fresh water was present at the surface but the seawater beneath was clear (C. Berg, personal communication). These observations, in conjunction with the low near-bed SSCs and RST collection rate measured at the South-central Reef Site approximately $600 \mathrm{~m}$ across the bay and low near-bed SSCs at the CRAMP Site during the flood suggest that, in the presence of low wave energy and little wind that was measured at the time, the positively buoyant (hypopycnal) plume could advect across the bay, but it produced negligible effects on sediment transport and accumulation on the bed in the western part of the bay.

The statistically significant relationship between RST collection rate and shear stress at the South-central Reef Site indicates that trap collection at this location was controlled in part by the resuspension of the surrounding seabed material. This observation is supported by the relationships between total shear stress and sediment grain size and composition, with coarser grain sizes collected during more energetic periods and a greater percentage of lower-density organic material collected in the RST during more quiescent periods. The sediment in the traps indicates that the collected terrigenous material at the South-central Reef Site was derived by advection, because the greater percentages of terrigenous material were collected when shear stresses were too low to cause resuspension $\left(<0.05 \mathrm{~N} / \mathrm{m}^{2}\right)$. The increase in fine-grained terrigenous sediment (from $<65 \%$ to $>72 \%$ ) and organic C (from $<3.1 \%$ to $>4.1 \%$ ) at this site began at the time of the flood and remained high for the remaining 31 days of the deployment (Fig. $6 \mathrm{~h}$ ). The reduced percentage of 
terrigenous material in the last sample, compared to samples since the August flood (Fig. 6g), suggests that the contribution of this flood material to the fine-grained, mobile suspended matter of the bay under these meteorologic and oceanographic conditions lasted about 1 month. The pattern is consistent with the scenario that flood-derived material initially deposited off the Wall and in the Black Hole was being transported clockwise past the South-central Reef Site following the low-frequency anti-cyclonic flow pattern in the bay (Fig. 3). Wave and current measurements made by Hoeke and Storlazzi (2007) along the Wall and along the western side of the bay during the following fall and winter showed that wave heights and current velocities in both the eastern and western portions of the bay were up to an order of magnitude greater than the summer period when large $(>4 \mathrm{~m})$ northwest winter storm waves impacted the bay. These current and wave-orbital velocities would likely be able to mobilize the thicker fine-grained flood deposits incorporated into the seabed (Draut et al., 2009), causing another period of high SSCs. The large waves, however, would also likely quickly advect the suspended terrigenous material out of the bay.

The recovery of new fine-grained terrigenous material only along the Wall and in the Black Hole in both the short and long cores collected in September (Cochran et al., 2007; Draut et al., 2006, 2009) suggests that while some of this fluvial material was advected away from this area past the South-central Reef Site, some portion of it remained in its initial depocenter and on potential coral recruitment sites on the Wall (as seen in the CIS imagery). Although some of the fine-grained terrestrial sediment was collected by the South-central Reef Site's RST in the weeks following the flood, significant long-term deposition of this fine-grained material and its incorporation into the seabed did not occur at the Southcentral Reef and CRAMP Sites, as evidenced by absence in the Cochran et al. (2007) and Draut et al. (2006, 2009) cores, likely due to the higher shear stresses at these more exposed sites.

Overall, these measurements and supporting data show that high SSCs in Hanalei Bay resulted from either resuspension of local seabed material or advection of flood material. High SSCs, however, did not always result in high sediment trap accumulation rates or net accumulation of sediment on the seabed. Furthermore, these results show that although the 2009 Hanalei River flood plume discussed here was very distinct in appearance, it was constrained close to the sea surface, flowed away from adjacent reefs, and quickly dissipated, similar to previous observations (Storlazzi et al., 2006; C. Berg, personal communication). Post-depositional reworking of the flood deposit by waves and currents, however, caused elevated suspended sediment concentrations near the seabed and close to coral communities for a greater duration than the surface plume's persistence in the bay.

Because of its duration and proximity to the seabed, reworked deposits potentially pose a greater long-term impact than the flood plume itself; similar findings were made by Field et al. (2008) on the extensive fringing reef off south Molokai, Hawaii. This fact should be taken into account when efforts for watershed restoration are planned to help reduce terrestrial sediment loading to adjacent coral reefsthat even if the terrestrial source is reduced, if not cut off, that the sediment may continue to impact the reefs for some time afterwards until the natural hydrodynamic processes can resuspend the sediment and advect it out of the coral reef system.

\subsection{Implications of observations to reef health}

In the more energetic western and southern portions of the bay, high shear stresses caused more carbonate sediment to be resuspended, causing high sediment trap collection rates relative to the Outer and Inner Wall Sites, but it did not allow for long-term accumulation of finergrained terrestrial material. The fact that a substantial (53-65\%) portion of the trapped sediment was terrestrial particles, which are likely underrepresented in the traps due to their slow settling velocities relative to the currents speeds and wave-orbital velocities, suggests that while significant volumes of terrigenous sediment are likely advected through this area, these particles do not reside on the seabed for long durations. While this fine-grained terrestrial sediment is not observed on the seabed during most conditions or incorporated in large amounts into the geologic record (Cochran et al., 2007; Draut et al., 2006, 2009), it is likely advected over the reefs, with the potential consequence of decreasing photosynthetically available radiation (PAR) and desorbing nutrients (De Carlo and Dollar, 1997) and/or contributing toxicants. Evidence for toxicity in deposits of terrestrial sediment from the Black Hole has been described by Carr et al. (2006), but no evidence was found in sediment elsewhere in the bay.

The low shear stresses measured in the eastern part of the bay during summer were not sufficient to flush fluvial sediment out of the bay quickly. The quiescent conditions allowed substantial short-term sediment deposition on reefs, hard surfaces, and the sea floor within the bay, requiring the corals to expend energy producing mucus to slough off sediment (Dodge et al., 1974; Dodge and Vaisnys, 1977; Rogers, 1990); evidence of this could be observed in the CIS imagery in the days following the flood. Because corals in the Hawaiian Islands spawn during summer (typically June-September; Kolinski and Cox, 2003) and require hard surfaces for new recruitment, this short-term sediment deposition that persisted at least for a month during the summer on suitable recruitment surfaces (as imaged by the CIS) likely resulted in reduced recruitment and diminished productivity of coral colonies in the eastern part of the bay.

As discussed by Rogers (1990), sediment "accumulation rates" (inferred from sediment traps) greater than $100 \mathrm{~g} / \mathrm{m}^{2} / \mathrm{d}$ are associated with fewer coral species, less live coral, and decreased net productivity. The STT collection rates at the four main study sites varied from 177 to $636 \mathrm{~g} / \mathrm{m}^{2} /$ day, approximately two to six times greater than the values quoted by Rogers (1990) as detrimental to reef health. Furthermore, during the August flood, the RST collection rate exceeded $510 \mathrm{~g} / \mathrm{m}^{2} /$ day for more than 4 days, potentially resulting in mortality of adult corals (Phillip and Fabricius, 2003). Dodge et al. (1974) noted that in some areas corals showed decreased growth rates when accumulation rates were greater than $10 \mathrm{~g} / \mathrm{m}^{2} / \mathrm{d}$, an order of magnitude lower than those discussed by Rogers (1990) and observed here. Other researchers (e.g., Marszalek, 1981) suggest that prolonged turbidity and the resulting chronic decreased photosynthetically available radiation (PAR) are more detrimental to corals than shortterm accumulation of sediment.

Piniak and Storlazzi (2008) observed that turbidities resulting from SSCs of $10 \mathrm{mg} / \mathrm{l}$ attenuated near-bed PAR more than $10 \%$ on the shallow $(\sim 1 \mathrm{~m})$ reef flat off the island of Molokai, negatively impacting coral photobiology by causing the corals' relative electron transport rate (rETR, a measure of photochemical efficiency) to decrease by just over $30 \%$. Although the mean SSC values in Hanalei Bay $(\sim 2 \mathrm{mg} / \mathrm{l})$ are one fifth those measured by Piniak and Storlazzi (2008), the greater depths (up to $10 \mathrm{~m}$ ) over the fore reefs in Hanalei Bay would likely result in a similar reduction in PAR and thus rETR for the same SSCs than on a shallow reef flat. The August Hanalei River flood, however, caused SSCs an order of magnitude greater $(100 \mathrm{mg} / \mathrm{l})$ over a much deeper water column and resulted in light penetration to decrease to less than $1.5 \mathrm{~m}$, suggesting that minimal incident light (and thus PAR) was reaching the corals along most of the Wall during this event. The two wave events during the summer that caused SSCs on the order of 5-20 mg/l reduced near-bed light penetration (as determined by the CIS) by $15-40 \%$. While we do not have specific measurements of the effect of suspended sediment on PAR and rETR in Hanalei Bay, the SSC data suggest that sediment resuspended from the seabed by waves or deposited by the Hanalei River likely contributes to reduced PAR levels over the deeper reefs in the bay, which could stress the coral ecosystem.

\subsection{The application of sediment traps to coral reef environments}

The potentially detrimental sediment trap accumulation rates discussed by Rogers (1990) were typically measured close $(<0.5 \mathrm{~m})$ to 
the seabed and thus are greater in value than what would be measured higher in the water column: at greater heights above the bed suspended sediment concentration decreases and both current speeds and waveorbital velocities are higher, thereby reducing trapping efficiency. This gradient is evident in the differences between the STT collection rates measured at two heights above bottom. The STTs with openings at $1.4 \mathrm{~m}$ above bottom at the Outer Wall and South-central Reef sites collected sediment at rates (in $\mathrm{g} / \mathrm{m}^{2} / \mathrm{d}$ ) 2.5 and 14 times lower, respectively, than co-located STTs with their openings at $0.4 \mathrm{~m}$ above bottom. Steeply decreasing gradients in trapping rates with increasing distance from the seabed are commonly observed (Gardner et al., 1983; Butman et al., 2004) and indicate that sediment resuspended from the adjacent seabed can be a primary source of material collected by traps. For comparison of trap collection rates in shallow, nearshore environments, it is important to standardize the trap designs and trap heights above bottom.

The limitations in applying sediment trap data to estimates of net "sedimentation rates" on a reef surface have often been de-emphasized. This is of concern to the coral reef research community, for sediment tube traps are commonly used by many researchers and regulatory agencies to determine "sedimentation rates" (e.g., Almada-Villela et al., 2003; Hill and Wilkinson, 2004). The findings presented here, along with previous studies (Gardner et al., 1983; White, 1990; and Jurg, 1996; Storlazzi et al., 2004; Bothner et al., 2006), suggest the following: (a) Sediment traps should have greater than a 10:1 length-to-width ratio, and all traps used within a study should have the same size and ratio; and (b) All sediment traps in a study should be deployed with their traps openings at a similar height above the seabed. In locations where current and wave-orbital speeds are sufficient to resuspend the adjacent seabed material, the trap collection rates must be analyzed in the context of the site's hydrodynamics to determine if the trapped material resulted from local resuspension or advected from some other location. Even with such standardization, interpretation of sediment trap collection rates appears difficult without geochemical analysis of the trapped sediment and concurrent, co-located measurements of the hydrodynamics.

\section{Conclusions}

The observations presented here show that variations in reef morphology relative to the orientation of the dominant meteorologic and oceanographic forcing can generate heterogeneous waves and currents over relatively small (hundreds of meters) spatial scales. These hydrodynamic gradients, in turn, can cause significant differences in the rates, modes, and timing of deposition, resuspension, and advection of both reef-derived and fluvial sediment over relatively short spatial scales unlike those observed along relatively linear sandy shorelines. It was shown that while elevated near-bed suspended sediment concentrations in this shallow coral reef embayment occurred due to both wave resuspension and floods, post-depositional reworking of flood deposit material can potentially cause the most harm to corals due to its proximity to the corals themselves and the longer duration of impact. These findings not only have implications for the influence of the different combinations of meteorologic and oceanographic forcing on hydrodynamics and sediment dynamics in a coral reef embayment, but also point out the difficulty in accurately interpreting sediment data in shallow-water environments that typify hermatypic coral reefs.

The timing and magnitude of sediment input to the coastal ocean relative to seasonal variations in wave and current energy has significant ecological consequences. Trade wind-induced orographic rainfall and floods often occur on high islands in the trade-wind belts during the summertime, and as shown here, the persistence of the resulting flood deposits can extend to a month's time during the dominant period of coral spawning in Hawaii. Anthropogenic modifications to the adjacent watersheds (overgrazing, poor development practices, introduced species, etc.) or climate change followed by quiescent oceanic conditions that typify summer periods can cause elevated sediment (and any associated chemicals and nutrients) loads to debauch into adjacent coastal waters. Because turbidity, sediment deposition, and burial of recruitment sites can place ecological stress on corals, these factors can decrease productivity and thereby affect the long-term health of coral reefs and their associated ecosystems.

\section{Acknowledgments}

This work was carried out as part of the US Geological Survey's Coral Reef Project as part of an effort in the U.S. and its trust territories to better understand the effects of geologic processes on coral reef systems. The U.S. Fish and Wildlife Service kindly provided storage space at the Hanalei National Wildlife Refuge's maintenance area for the USGS equipment during the course of the two and a half years of field operations in Hanalei Bay. Carl Berg (previously at the Hanalei Watershed Hui) was a major contributor to every aspect of the fieldwork and coordinating our efforts with the numerous other institutions working in the Hanalei watershed-reef system. Susie Cochran, Josh Logan, Rick Rendigs, Hank Chezar, Thomas Reiss, and Dave Gonzales (USGS) assisted with the fieldwork and instrumentation. Sandra Baldwin, Olivia Buchan, Michael Casso, Harland Goldstein, Kate Mc Mullen, Jiang Xiao (USGS) and Steve Manganini (WHOI) performed the laboratory analyses on the sediment samples. Jill Nishimura, Heather Jeppesen, and Barry Hill (USGS) provided information on water and sediment discharge from the USGS Hanalei River stream gauge. Hanalei residents Charles Bass, Garrett Santos, Ryan Siebring, and Earl Loder are thanked for boat operation and assistance. Matt Rosener (previously at the Hanalei Watershed Hui) cleaned the optics of the OBSs and CIS. We would also like to thank Patrick Barnard (USGS), Jon Warrick (USGS), and Greg Piniak (NOAA), who contributed numerous excellent suggestions and a timely review of our work. Use of trademark names does not imply USGS endorsement of products.

Metadata for these field activities can be found at:

http://walrus.wr.usgs.gov/infobank/s/s106 ka/html/s-1-06-ka. meta.html.

http://walrus.wr.usgs.gov/infobank/s/s206 ka/html/s-2-06-ka. meta.html.

\section{References}

Acevedo, R.J., Morelock, J., Olivieri, R.A., 1989. Modification of coral reef zonation by terrigenous sediment stress. Palios 4, 92-100.

Almada-Villela, P.C. Sale, P.F. Gold-Bouchot, G. Kjerfve, B, 2003. Manual of Methods for the MBRS Synoptic Monitoring Program-Selected Methods for Monitoring Physical and Biological Parameters for Use in the Mesoamerican Region: Mesoamerican Barrier Reef Systems (MBRS) Project Technical Document No. 4, Belize City. http://ocean.tamu. edu/images/profiles/kjerfve/other/202.pdf.

Baker, E.T., Milburn, H.B., Tennant, D.A., 1988. Field assessment of sediment trap efficiency under varying flow conditions. J. Mar. Res. 46, 573-592.

Bjorgesaeter, A., Gray, J.S., 2008. Setting sediment quality guidelines: a simple yet effective method. Mar. Poll. Bull. 57, 221-235.

Bothner, M.H., Reynolds, R.L., Casso, M.A., Storlazzi, C.D., Field, M.E., 2006. Quantity, composition, and source of sediment collected in sediment traps along the fringing coral reef off Molokai, Hawaii. Mar. Poll. Bull. 52, 1034-1047.

Buddemeir, R.W., Hopley, D., 1998. Turn-ons and turn-offs: causes and mechanisms of the initiation and termination of coral reef growth. Proceedings of the 6th International Coral Reef Congress, pp. 253-261.

Butman, B., Bothner, M.H., Alexander, P.S., Lightsom, F.L., Martini, M.A., Gutierrez, B.T. Strahle, W.S., 2004. Long-term observations in western Massachusetts Bay offshore of Boston, Massachusetts: data report for 1989-2002. USGS Digital Data Series DDS74, Version 2. http://pubs.usgs.gov/dds/dds74/.

Calhoun, R.S., Fletcher, C.H., 1999. Measured and predicted sediment yield from a subtropical, heavy rainfall, steep-sided river basin: Hanalei, Kauai, Hawaiian Islands. Geomorphology 30, 213-226.

Calhoun, R.S., Fletcher, C.H., Harney, J.N., 2002. A budget of marine and terrigenous sediments: Hanalei Bay, Kauai, Hawaiian Islands. Sediment. Geol 150, 61-87.

Carr, R.S., Nipper, M., Field, M., Biedenbach, J.M., 2006. Coastal circulation and sediment dynamics in Hanalei Bay, Kauai, Part III, studies of sediment toxicity. U.S. Geological Survey Open-File Report 2006-1147. http://pubs.usgs.gov/of/2006/1147/.

Cochran, S.A., Field, M.E., Storlazzi, C.D., 2007. Distribution of mud in Hanalei Bay, Kauai: June vs. September, 2006. In: Field, Michael, E., Berg, Carl S., Cochran, Susan A. (Eds.), 
Science and Management in the Hanalei Watershed; A Trans-disciplinary Approach. Proceedings from the Hanalei Watershed Workshop, 21-22 February 2007, Hanalei HI, U.S. Geological Survey Open File Report 2007-1219, pp. 18-21. http://pubs.usgs. gov/of/2007/1219/.

De Carlo, E.H., Dollar, S.J., 1997. Assessment of suspended solids and particulate nutrient loading to surface runoff and the coastal ocean in the Honokowai Drainage Basin, Lahaina District, Maui. Final report to NOAA/Algal Blooms Project and Hawaii State $\mathrm{DOH}$.

DeFelice, R.C., Parrish, J.D., 2001. Physical processes dominate in shaping invertebrate assemblages in reef-associated sediments of an exposed Hawaiian coast. Mar. Ecol. Progr. Series 215, 121-131.

Dodge, R.E., Aller, R.C., Thompson, J., 1974. Coral growth related to suspension of bottom sediments. Nature 247, 574-577.

Dodge, R.E., Vaisnys, J.R., 1977. Coral populations and growth pattern: responses to sedimentation and turbidity associated with dredging. J. Mar. Res. 35, 715-730.

Draut, A.E., Field, M.E., Bothner, M.H., Logan, J.B., Casso, M.A., Baldwin, S.M., Storlazzi, C.D., 2006. Coastal Circulation and Sediment Dynamics in Hanalei Bay, Kauai, Hawai i, Part II, Tracking Recent Fluvial Sedimentation: Isotope Stratigraphy Obtained in Summer 2005 U.S. Geological Survey Open-File Report 2006-1125. http://pubs.usgs.gov/of/2006/ $1125 /$.

Draut, A.E., Bothner, M.H., Reynolds, R.L., Field, M.E., Cochran, S.A., Logan, J.B., Storlazzi, C.D. Berg, C.J., 2009. Supply and dispersal of seasonal flood deposits in Hanalei Bay, Kauai, HI, USA: implications for coral-reef ecosystems. Geol. Soc. Am, Bull 121 (3-4), 574-585.

Fabricius, K.E., 2005. Effects of terrestrial runoff on the ecology of corals and coral reefs: review and synthesis. Mar. Poll. Bull. 50, 125-146.

Fabricius, K.E., Wolanski, E., 2000. Rapid smothering of coral reef organisms by muddy marine snow. Estuarine. Coastal Shelf Sci 50, 115-120.

Field, M.E., Bothner, M.H., Chevez, P.S., Cochran, S.A., Jokiel, P.L., Ogston, A.O., Presto, M.K. Storlazzi, C.D., 2008. The effects of a Kona storm on the Molokai Reef: November and December 2001. In: Field, M.E., Cochran, S.A., Logan, J.B., Storlazzi, C.D. (Eds.), The Coral Reef of South Molokai, Hawaii-Portrait of a Sediment-threatened Fringing Reef. U.S. Geological Survey Scientific Investigation Report 2007-5101. http://pubs.usgs.gov/ $\operatorname{sir} / 2007 / 5101 /$

Fortes, M., 2000. The effects of siltation on tropical coastal ecosystems. In: Wolanski, E. (Ed.), Oceanographic Processes of Coral Reefs. InCRC Press, Boca Raton, pp. 93-112

Friedlander, A.M., DeFelice, R.C. Parrish, J.D. Frederick, J.L, 1997. Habitat resources and recreational fish populations at Hanalei Bay, Kauai. Final Report submitted to the Hawai i Department of Land and Natural Resources, Division of Aquatic Resources

Friedlander, A.M., Brown, E.K., Helweg, D.A., 2005. Hanalei Bay marine benthic communities since 1992: spatial and temporal trends in a dynamic Hawaiian coral reef ecosystem. Hawaii Cooperative Studies Unit Technical Report. Hawaii Cooperative Studies Unit Pacific Aquaculture and Coastal Resources Center, University of Hawai i at Hilo.

Gardner, W.D., Richardson, MJ., Hinga, K.R., Biscaye, P.E, 1983. Resuspension measure with sediment traps in a high-energy environment. Earth Planet. Sci. Lett. 66, 262-278.

Geyer, W.R., Hill, P., Milligan, T., Traykovski, P., 2000. The structure of the Eel River plume during floods. Continent. Shelf Res. 20, 2067-2093.

Harrington, L., Fabricius, K., Eaglesham, G., Negri, A., 2005. Synergistic effects of diuron and sedimentation on photosynthesis and survival of crustose coralline algae. Mar. Poll. Bull. 51, 415-427.

Hill, J., Wilkinson, C., 2004. Methods for Ecological Monitoring of Coral Reefs: A Resource for Managers, Version 1. Townsville. Australian Institute of Marine Science. http:// aims.gov.au/pages/facilities/bookshop/monitoring-methods/pdf/methods1000000.pdf.

Hoeke, R.A.,Storlazzi, C.D., 2007. Hydrodynamic modeling of Hanalei Bay. In: Field, Michae E., Berg, Carl S., Cochran, Susan A. (Eds.), Science and Management in the Hanale Watershed; A Trans-disciplinary Approach: Proceedings from the Hanalei Watershed Workshop, 21-22 February 2007, Hanalei, HI, U.S. Geological Survey Open File Report 2007-1219, pp. 44-46. http://pubs.usgs.gov/of/2007/1219/.

Jones, R., 2005. The ecotoxicological effects of Photosystem II herbicides on corals. Mar. Poll Bull. 51, 495-506.

Jurg, B., 1996. Towards a new generation of sediment traps and a better measurement/ understanding of settling particle flux in lakes and oceans: a hydrodynamical protocol. Aquatic Sci. 58 (4), 283-296.
Kolinski, S.P., Cox, E.F., 2003. An update on modes and timing of gamete and planula release in Hawaiian Scleractinian corals with implications for conservation and management. Pacific Sci 57, 17-27.

Madsen, O.S., 1999. Coastal sediment transport processes. American Society of Civil Engineers Short Course, Coastal Sediments '99 Conference. InNew York.

Marszalek, D.S., 1981. Impact of dredging on a subtropical reef community: Southeastern Florida, U.S.A. Proceedings of the 4th International Coral Reef Congress, pp. 147-153.

McCulloch, M. Fallon, S. Wyndham, T., Hendey, J., Lough, J., Barnes, D., 2003. Coral record of increased sediment flux to the inner Great Barrier Reef since European settlement. Nature 421, 727-730.

McLane Research Laboratories, Inc., 2004. Time-series Sediment Trap. Description available online at: http://www.mclanelabs.com/mark78 g21.html.

Milliman, J.D., Syvitski, J.P.M., 1992. Geomorphic/tectonic control of sediment discharge to the ocean-the importance of small mountainous rivers. Journal of Geology 100, $1-21$.

Moberly, R.M., Chamberlain, T., 1964. Hawaiian beach systems. Hawaii Institute of Geophysics Report HIG 64-2. University of Hawai i. 177 pp.

National Data Buoy Center, National Oceanographic and Atmospheric Administration, 2006. Historical Hourly Data for NW Hawaii Station \#51001. online, dataset, http:// www.ndbc.noaa.gov/station_history.php?station $=51001$.

Ogston, A.S., Storlazzi, C.D., Field, M.E., Presto, M.K., 2004. Currents and suspended sediment transport on a shallow reef flat: South-central Molokai, Hawaii. Coral Reefs 23, 559-569.

Pacific Islands Water Science Center, U.S. Geological Survey, 2006. Daily Stream Flow and Sediment Discharge Data for Hawaii. online, dataset, http://waterdata.usgs. gov/hi/nwis/sw.

Phillip, E., Fabricius, K.E., 2003. Photophysiological stress in scleractinian corals in response to short-term sedimentation. J. Experiment. Mar. Biol. Ecol. 287, 57-78.

Piniak, G.A., 2007. Effects of two sediment types on the fluorescence yield of two Hawaiian scleractinian corals. Mar. Environ. Res. 64, 456-468.

Piniak, G.A., Brown, E.K., 2008. Growth and mortality of coral transplants (Pocillapora damicornis) along a range of sediment influence in Maui, Hawaii. Pacific Sci. 62, $39-55$

Piniak, G.A., Storlazzi, C.D., 2008. Diurnal variability in turbidity and coral fluorescence on a fringing reef flat: Southern Molokai, Hawaii. Estuarine Coast. Shelf Sci. 77 (1), $56-64$.

Poppe, L.J., Elaison, A.H., Fredericks, J.J., Rendigs, R.R., Blackwood, D., Polloni, C.F., 2000. Grain size analysis of marine sediments: methodology and data processing. In U.S. Geological Survey East Coast sediment analysis: procedures, database, and georeferenced displays. U.S. Geological Survey Open File Report 00-358. http://pubs. usgs.gov/of/2000/of00-358/.

Rogers, C.S., 1990. Responses of coral reefs and reef organisms to sedimentation. Mar. Ecol. Progr. Series 62, 185-202.

Storlazzi, C.D., Ogston, A.S., Bothner, M.H., Field, M.E., Presto, M.K., 2004. Wave- and tidallydriven flow and sediment flux across a fringing coral reef: South-central Molokai, Hawaii. Continen. Shelf Res. 24 (12), 1397-1419.

Storlazzi, C.D. Presto, M.K., Logan, J.B. Field, M.E., 2006. Coastal circulation and sediment dynamics in Hanalei Bay, Kauai. Part I: Measurements of Waves, Currents, Temperature, Salinity and Turbidity: June-August, 2005. U.S. Geological Survey Open-File Report 2006-1085. http://pubs.usgs.gov/of/2006/1085/.

Storlazzi, C.D., Presto, M.K., Bothner, M.H., Logan, J.B., Field, M.E., 2008. Coastal circulation and sediment dynamics in Hanalei Bay, Kauai. Part IV: measurements of waves, currents, temperature, salinity and turbidity: June-September, 2006. U.S. Geological Survey Open-file Report 2008-1220. http://pubs.usgs.gov/of/2008/1220/.

Warrick, J.A., Xu, J.P., Noble, M.A., Lee, H.J., 2008. Rapid formation of hyperpycnal sediment gravity currents offshore a semi-arid California River. Continent. Shelf Res. 28, 991-1009.

White, J., 1990. The use of sediment traps in high-energy environments. Mar. Geophys. Res. 12, 145-152.

Wolanski, E., 1994. Physical Oceanographic Processes of the Great Barrier Reef. CRC Press, Boca Raton. 356 pp.

Wolanski, E., Richmond, R.H., Davis, G., Bonito, V., 2003. Water and fine sediment dynamics in transient river plumes in a small, reef-fringed bay, Guam. Estuarine, Coast Shelf Sci 56 (5-6), 1029-1040. 